\title{
HISTÓRIAS DE VIDA DE MENINAS COM EXPERIÊNCIA PREGRESSA NAS RUAS: PERSPECTIVAS DO PROCESSO DE INCLUSÃO SOCIAL ${ }^{1}$
}

\author{
LIFE HISTORIES OF GIRLS WITH EXPERIENCE OF LIFE IN THE STREETS: PERSPECTIVES TO THE \\ INCLUSION SOCIAL PROCESS
}

\section{HISTORIAS DE VIDA DE MUCHACHAS CON EXPERIENCIA ANTERIOR EN LAS CALLES: PERSPECTIVAS DEL PROCESO DE INCLUSIÓN SOCIAL.}

\section{Normalene Sena de Oliveira ${ }^{2}$, Marcelo Medeiros ${ }^{3}$}

RESUMO: Trata-se de um estudo qualitativo que aborda historia de vida de oito meninas com experiência pregressa nas ruas e seu processo de inclusão social. Apresentamos como objetivos: analisar o significado de reintegração social; identificar as ações pedagógicas da instituição no processo de reintegração social; conhecer o significado e o impacto da recuperação social para meninas com experiência de vida nas ruas. A coleta de dados ocorreu através da entrevista semiestruturada, diário de campo e observação participante. Os resultados mostram que o resgate e o processo de inclusão social dos sujeitos são possíveis a partir da relação interpessoal do educador com estes em seu meio. Assim, entendemos que apesar de uma história de vida marcada pelo abandono e exclusão social, o despertar de novas perspectivas de vida ocorre devido às ações pedagógicas e o fortalecimento das relações interpessoais entre as meninas e os educadores inseridos neste processo de reintegração social.

PALAVRAS-CHAVE: Crianças de Rua, Ajustamento Social, Enfermagem em Saúde Pública.

ABSTRACT: It is a qualitative study approaching the life histories of eight girls with living experience in the streets and their social inclusion process. The objectives of this research was to analyze the meaning of social reintegration; to identify the pedagogic actions of the institution in the process of social reintegration; to know the meaning and the impact of the social recovery for girls with life experience in the streets. The collection of data was developed by semi-structured interview, field diary and participant observation. The results showed that the rescue and the process of social inclusion of the subjects is possible starting from the educator's relationship interpersonal with these into the institution. Thus, we understand that in despite of a life history marked by the abandonment and social exclusion, the awakening of new life possibility occurs because the pedagogic actions and interrelationship empowerment among the girls and educators inserted in this reintegration social process.

KEY WORDS: Homeless Youth, Social Adjustment, Public Health Nursing.
RESUMEN: Es un estudio cualitativo sobre las historias de vida de ocho muchachas con experiencia de vida en las calles y el proceso de inclusión social logrados por las mismas. Los objetivos de esta investigación fueran: analizar el significado de reintegración social; identificar las acciones pedagógicas de la institución en el proceso de reintegración social; conocer el significado y el impacto de la recuperación social de las muchachas con experiencia de vida en las calles. La colecta de datos he sido cumplida a través de la entrevista semiestructurada, diario del campo y observación participante. Los resultados mostraran que el rescate y el proceso de inclusión social de las muchachas son posibles iniciando-se en la relación interpersonal del educador con estas muchachas en su hábitat. Así entendemos que a pesar de una historia de vida marcada por el abandono y la exclusión social, el despertar de una nueva posibilidad de vivir ocurre debido a las acciones pedagógicas e el fortalecimiento de las interrelaciones interpersonales entre las muchachas e los educadores inseridos en esto proceso de reintegración social.

PALABRAS CLAVE: Jóvenes sin Hogar, Ajuste Social, Enfermería en Salud Pública.

\footnotetext{
${ }^{1}$ Artigo baseado em Dissertação apresentada ao Programa de Pós-Graduação - Mestrado em Enfermagem da Faculdade de Enfermagem da Universidade Federal de Goiás. Goiânia, GO. A execução deste texto contou com apoio CAPES.

${ }^{2}$ Enfermeira, Mestra em Enfermagem pela Universidade Federal de Goiás. Diretora da "Casa Talitha-Kum" de assistência à criança e ao adolescente em situação de risco social. e-mail: normalene@bol.com.br

3 Enfermeiro,Doutor em Enfermagem, Professor Adjunto da Faculdade de Enfermagem da Universidade Federal de Goiás. Goiânia, GO. e-mail: marcelo@fen.ufg.br
} 


\section{INTRODUÇÃO}

Ao convivermos com a realidade da criança e adolescente em situação de rua e seu processo de resgate e inclusão social verificamos uma população marcada pela exclusão e abandono familiar em decorrência da desestrutura em todos os níveis.

Neste contexto vamos encontrar em situação de rua segundo a caracterização realizada por LUSK (1989) meninos e meninas que trabalham na rua e vão rompendo os laços familiares e aprofundando no mundo da rua com sua cultura e valores próprios; meninos e meninas sem vínculo familiar e outros que acompanham suas famílias na rua. Daí a importância do educador social neste espaço para estabelecer uma relação interpessoal junto aos grupos e por meio de atividades educativas potencializar valores que motive o resgate da auto-estima e conseqüentemente a saída da rua. Uma vez que a rua se apresenta como espaço de "liberdade" e desenvolvimento de habilidades específicas do meio com sua cultura própria.

Ao tratarmos do resgate, FERREIRA (1989) o define como o ato ou efeito de resgatar. Tratando-se do trabalho junto à criança e adolescente em situação de rua podemos defini-lo como meios que possibilitam a pessoa a assumir a própria história de vida e com autonomia para serem sujeitos da própria história, processo este desencadeado por uma motivação interna, pessoal, em que a pessoa ou instituição que favorece esta possibilidade deverá respeitar a liberdade e a caminhada de cada sujeito, sendo agente motivador para que a pessoa faça o próprio caminho.

Embora não tenhamos encontrado na literatura contribuições que aprofundem esse aspecto estudado, acreditamos que seja importante neste processo a consciência de que cada indivíduo deve ser livre para realizar escolhas e estas devem ser assumidas de acordo com a capacidade e opção da pessoa.

Ressaltamos ainda a importância da pedagogia social de rua como ferramenta motivadora do despertar de novas possibilidades junto a realidade da criança e adolescente em situação de rua, como também a possibilidade em responder efetivamente as necessidades apresentadas por estas pessoas no seu universo.

De modo que as instituições possam assumir a defesa da vida (RIZZINI et al, 2005) e o respeito ao ser pessoa, contribuindo para que tenham claras as motivações que direcionam suas escolhas e encorajálos para que possam enfrentar os conflitos pessoais e que estas opções não sejam condicionadas pelo ambiente, fatores econômicos, sociais, institucionais, ou por uma auto-estima prejudicada, mas seja uma escolha livre e pessoal. Assim, REMEN (1993), nos alerta que muitas vezes estas escolhas podem sofrer influências sociais, pelos papéis que desempenhamos, idade, cultura, crenças, valores, sentimentos, desejos, e tendências, como também o próprio ambiente.

É importante sabermos que nesta trajetória, também somos aprendizes e que cada pessoa tem um processo e este depende de como assumimos nossa história de vida. Mas nem sempre estamos capacitados para fazermos escolhas que exigem confronto, coragem e determinação, contudo podemos desenvolver habilidades para isto a partir do momento que somos motivados a fazê-lo e nos autodetermine a realizar.

Sendo assim, a relação interpessoal proporcionará mudanças entre pessoas que se encontram envolvidas; isto nos faz afirmar que o menino e a menina em situação de rua não é alguém vazio, sem potencialidades, que está ali apenas para receber, pelo contrário está também para nos ajudar a mudar a nós mesmos e a vermos a vida de um outro ângulo que certamente não seria possível sem a ajuda deles.

WALDOW (2001), ao trabalhar historicamente a evolução do cuidado humano, apresenta-o como responsabilidade da mulher. Com o passar do tempo, olhando o mundo com uma visão atual, capitalista, percebemos o descuidar do ser humano em relação a ele mesmo e a sociedade, o que acarreta no cotidiano uma desestrutura política, econômica e social e, conseqüentemente, a des-humanização e a invasão cultural nas populações menos favorecidas. Muitas vezes pensamos que cuidar é impor o nosso saber, achando que o outro sabe menos. Esta é uma crença baseada no preconceito e na relação de poder em detrimento aos valores do indivíduo como pessoa humana, portadora de direitos e deveres, com potencialidades a serem desenvolvidas.

Como seres humanos e profissionais de saúde, somos convocados a resgatar o processo histórico do cuidar e nos atualizarmos em nossa história, levando o cuidar a uma evolução semelhante a que as ciências têm sofrido nas últimas décadas, para que assim, possamos crescer no auto-conhecimento e desenvolvimento das diversas habilidades que nos capacita para um cuidar que rompe todas as estruturas que não vão de encontro com a dignidade humana.

O papel da Enfermagem é fundamental neste contexto de exclusão e marginalização uma vez que suas ações estão ligadas diretamente com o sujeito. E aqui destacamos a relevância do trabalho de HIRATA (1999) junto ao Adolescente "não cidadão", na perspectiva do cuidado em vista da construção da cidadania, uma vez que atuar com estes grupos requer algumas exigências como, a sensibilidade, abertura, parcerias, mas acima de tudo a predisposição para criar laços (OLIVEIRA et al, 2004).

Mediante o exposto é relevante à reflexão da relação interpessoal que MIRANDA \& MIRANDA (1995) faz ao afirmar que parte do que somos é 
resultado das relações que conseguimos estabelecer em nossa vida, sejam elas positivas ou não. Sendo assim, quais as marcas que as crianças e adolescentes que vivenciam este processo de exclusão carregam das relações/ interações que têm ou tiveram com a sociedade, a família e a própria situação de pobreza?

A realidade de vida deste grupo é marcada por uma história pessoal de exclusão, violência social, psicológica, física, fruto da miséria e da desestrutura em todos os níveis em que vive. Segundo CÂMARA (2003, p. 7):

\begin{abstract}
"Adolescentes vulneráveis, por seus contextos sociais e impossibilidades econômicas, trazem em seus corpos e em suas formas de perceber o mundo a marca da violação de seus direitos instituídos constitucionalmente. São indivíduos que passam cotidianamente e de alguma forma em aparatos de apoio social, seja na unidade básica de saúde, no hospital, na escola, em serviços sociais de suplementação de renda, em núcleos de apoio social, na igreja, etc,requisitando invariavelmente uma atenção integral às suas necessidades, sendo estas referentes não só ao seu processo de desenvolvimento e maturação física, psíquica, moral e intelectual, próprias da idade, mas também relacionadas às suas necessidades específicas demandadas pelas suas condições sociais e econômicas".
\end{abstract}

Para realizarmos este trabalho partimos do pressuposto que cada criança e adolescente em situação de rua carregam em si, um universo de potencialidades que quando despertadas fazem emergir um mundo de sonhos, acompanhados pela coragem e determinação, vislumbrando outras possibilidades de vida. (OLIVEIRA, 2004).

Por este motivo nos sentimos motivados a aprofundar um pouco do processo de recuperação desta população, os desafios, as conquistas e mesmo a luta travada por estas pessoas para romperem com o vínculo das drogas e grupos de convivência neste contexto. Como profissionais de saúde na área da Enfermagem sentimo-nos interpelados a conhecer melhor este fenômeno e ao mesmo tempo apresentar histórias de vida que passaram por este processo e que hoje se encontram em uma outra luta, que é a sobrevivência num contexto pouco favorável a inclusão social.

Para que possamos compreender o que foi vivenciado na vida dessas crianças e adolescentes apresentamos neste estudo o itinerário vivenciado por eles até o momento. Como de fato era a vida na rua, em suas famílias, e o que desencadeou a saída do suposto "lar".

Sendo assim, ao estabelecermos relações interpessoais positivas no habitat destas pessoas, com elas interagirmos como alguém que faz parte do grupo. Desenvolvemos atividades educativas em todas as etapas do seu itinerário, com presença motivadora da auto-estima positiva, viabilizamos junto às mesmas, as predisposições pessoais para a saída da rua e o resgate da própria história, e como praticar o exercício da cidadania.

Para este estudo, que consiste de um fragmento de um estudo maior (OLIVEIRA, 2006), estabelecemos como objetivos analisar o significado de reintegração social; identificar as ações pedagógicas da instituição no processo de reintegração social; conhecer o significado e o impacto da recuperação social para meninas com experiência de vida nas ruas.

Acreditamos que por meio das histórias vida que a serem apresentadas nos oferecerá possibilidades em conhecermos os desafios, as lutas e esperanças da criança e adolescente do nosso país e a capacidade de superação dos limites desta população quando são motivadas por uma pedagogia que viabiliza o encontro consigo, com o outro e com o mundo na perspectiva da reconstrução da própria história.

\section{METODOLOGIA}

Para o alcance dos objetivos nos pautamos em uma abordagem qualitativa de investigação que, neste caso a opção foi a proposta da História Oral de Vida, uma vez que possibilita ao indivíduo reconstruir eventos da vida e atribuir significado a eles por meio da elaboração de uma narrativa; onde há liberdade de refletir e repensar sua própria história (REINALDO, 2003; MEIHY,2002). De modo semelhante, MINAYO (1992, p.127) afirma que "a história de vida pode ser o melhor método para se estudar processos de socialização, emergência de um grupo, estrutura organizacional, nascimento e declínio de uma relação social e respostas situacionais a contingências cotidianas".

Sendo assim, acreditamos ser oportuno e motivador trabalharmos com este método, tendo em vista a população que vivencia um processo em diversas etapas da vida. BOTELHO (2003, p.74) afirma que "na história de vida, além da noção de processo, a riqueza de detalhes que pode advir das informações coletadas junto aos sujeitos, pode sugerir novas variáveis, novas questões e novos processos que podem conduzir a uma reorientação da área".

Ainda segundo REINALDO (2003, p.56), a História Oral teve seu início após a Segunda Guerra Mundial, cujo marco foi à criação formal do primeiro Projeto de História Oral, pela Universidade de Columbia, Nova York, onde foram relatadas "experiências vividas por ex-combatentes, familiares e vítimas da Guerra, através de relatos orais cujo objetivo era registrar e conhecê-las".

\section{Campo de estudo}




\section{Realidade Social}

A criança e o adolescente em situação de rua vivem em uma realidade onde muitas vezes são consideradas, em um plano de políticas públicas e/ou por determinados grupos social, como peças descartáveis de um mundo em processo acelerado no desenvolvimento tecnológico, que excluí, explora e lança sem piedade milhões de famílias para a linha abaixo da miséria. Isto significa que suas famílias residem nas periferias dos centros urbanos, onde a mãe assume o papel de chefe da casa, tendo como rotina os conflitos pela ausência de dinheiro, trabalho, saúde e educação o que gera na convivência situações de miséria e exclusão. (OLIVEIRA, 2001). Assim como em outros grandes centros do país, a cidade de Goiânia capital do estado de Goiás, palco de nosso estudo, parte da população também sofre tais conseqüências nesse processo que exclui aqueles que não têm acesso ao trabalho, à habitação digna, à alimentação, e serviços de saúde, educação entre outros.

Essa situação remete muitas pessoas a procurarem as ruas para que, por meio de atividades licitas ou ilícitas, consigam alimentos, roupas, moradia; mas naquele espaço se sujeitam à violência implícita no meio (MEDEIROS, 1999; CÂMARA, 2003; OLIVEIRA et al, 2004). Entre essas pessoas estão crianças e adolescentes que associados a esses fatores a convivência em um lar desestruturado com pais ou padrastos e mães alcoólatras, desempregados, comprometidos com a justiça, e sem nenhuma estrutura econômica, física e psicológica para serem educadores, como também a ausência de autonomia para gerir a própria vida, encontrem nas ruas um mecanismo de sobrevivência. (MEDEIROS, 1999; OLIVEIRA et al, 2004); (OLIVEIRA,2004a . 2004b. 2004c.).

Várias iniciativas propõem o resgate dessas crianças e adolescentes. Entre elas, as Casas de Passagem (CÂMARA, 2003; OLIVEIRA, 2006) que se referem às instituições em que o menino ou a menina em menoridade pode estar por um pequeno período aguardando para serem encaminhados para a família ou para um abrigo em caráter mais definitivo. Neste contexto elegemos como campo de estudo o espaço onde hoje vivem meninas que um dia estiveram na rua e fizeram o acompanhamento com a "Tenda" (nome fictício da Organização Não Governamental ONG - onde desenvolvemos nosso trabalho de campo), em todas as etapas até a conquista da casa própria, trabalho, enfim, condições de assumirem o controle da própria vida com dignidade.

A Tenda possui característica principal ser um lugar de acolhida, resgate da cidadania, oposição a um sistema político, econômico e social míope, em prol a defesa da vida e o entrelaçamento de parcerias para desconstruir a exclusão social, cujo trabalho é conduzido por um grupo religioso.

\section{Trabalho de campo}

Os sujeitos da pesquisa foram oito meninas de 16 a 22 anos com história de vida pregressa na rua. Todas são mães de 1 a 5 filhos, na maioria dos casos, de pais diferentes. Elas fizeram o processo de recuperação e inserção social na "Tenda".

Os sujeitos foram identificados por nomes fictícios da flora e fauna do cerrado, símbolos de força, resistência e beleza. São pessoas que frente aos desafios de uma história de vida retalhada, aparentemente irreconstituível como o cerrado em período de seca, é capaz de florescer, ressurgir das cinzas, dar beleza aos campos com sua capacidade de reconstruir a partir de perdas e experiências profundamente dolorosas.

A coleta dos dados foi realizada por meio de entrevista semi-estruturada, observação participante e diário de campo, por um período de três meses. Segundo MINAYO (1992, p.126), nestas abordagens o pesquisador interage constantemente com o informante. É aquele que combina observação, relatos introspectivos de lembranças, relevâncias e roteiros mais ou menos centrados em algum tema. (...) Os pressupostos que validam a história de vida são da mesma natureza dos que fundamentam a entrevista e a observação participante.

Para realizarmos esta etapa da investigação permanecemos na residência dos sujeitos por um período mínimo de tres a sete dias. Isso foi possível devido à proximidade que existe há tempos entre a pesquisadora e os sujeitos uma vez que convivemos com as pessoas em vários momentos e também fizemos parte de seu processo de reintegração social. Foram as proprias meninas quem estabeleceu o melhor período e a melhor maneira de coletarmos os dados. A coleta em si, ocorreu por meio de um momento específico de entrevista aberta semiestruturada. A observação participante e anotações em diário de campo foram desenvolvidas ao longo de nossa permanência na residência de forma que complementasse os dados coletados na entrevista.

Por sua vez, as entrevistas foram gravadas em fita cassete e transcritas na integra. Posteriormente iniciamos o processo de análise por meio de três etapas: pré-entrevista, entrevista propriamente dita, e as transcrições das falas. Posteriormente, por meio da leitura exaustiva do material transcrito e das anotações no diário de campo, iniciamos o processo de categorização e identificação dos significados inerentes ao nosso objeto de estudo. Emergiram da fala dos autores alguns núcleos temáticos, que segundo BARDIN (1977, p. 105-106) o define como uma unidade de significação que se liberta naturalmente de um texto analisado segundo certos critérios relativos a teoria que serve de guia e leitura, sendo, geralmente, utilizado como unidade de registro para estudar motivações de opiniões, de atitudes, de valores, de crenças, de tendências, entre outros. Assim foi possível identificarmos em meio às falas, 
três categorias que nos permite apresentar a vida destas pessoas. São elas, "a vinda para a rua", "a vida na rua" e "a vida além da rua".

A todos os sujeitos o sigilo quanto à identidade, para resguardar seus direitos e sua privacidade. Como também consideramos os aspectos éticos da resolução CNS 196/96. O Projeto de Pesquisa foi analisado pelo Comitê de Etica em Pesquisa Médica Humana e Animal do Hospital das Clínicas da Universidade Federal de Goiás, sendo aprovado de acordo com o registro $n^{0} 131 / 2004$.

\section{RESULTADOS E DISCUSSÃO}

Para melhor compreendermos os objetivos deste estudo, trazemos os resultados e discussões das historias de vida e seu processo de inclusão social, organizados em dois momentos, onde apresentamos a "Tenda" como um espaço de acolhida, suporte e potencialização de valores e resgate na reestruturação de vida das adolescentes", e ainda neste momento os sujeitos do estudo.

No segundo, analisamos as narrativas dos fragmentos das historias de vida das meninas a partir de suas narrativas, por meio das categorias temáticas que emergiram no processo de análise. $\mathrm{Na}$ transcrição das falas dos sujeitos optamos por não fazer nenhuma correção gramatical, no sentido de respeitarmos a linguagem própria dos mesmos que ainda trazem consigo influência de expressões verbais próprias, de quem viveu em um contexto de rua, e conforme explicitamos, os fragmentos das falas dos sujeitos foram diferenciados segundo o entrevistado atribuindo-lhes nomes fictícios.

\section{A "TENDA" NO PROCESSO DE REINTEGRAÇÃO}

A "Tenda" é uma Instituição filantrópica inaugurada em 13 de maio de 1998, tendo recebido a primeira menina no dia 16 de maio de 1998. Surgiu a partir das necessidades apresentadas pelas meninas em situação de rua desde 1996, as quais não possuíam vínculos familiares, estavam grávidas e preocupadas com a possibilidade da perda de seus filhos para o Juizado da Infância e Juventude por viverem nesta situação. Solicitavam ajuda para mudar de vida e conseqüentemente a ausência de uma Instituição que pudesse acolher mãe e filho num processo de inclusão social, e as próprias adolescentes e jovens deste contexto.

A "Tenda" não possui caráter de privação de liberdade por acreditarmos em uma pedagogia que educa para a autonomia e liberdade, onde cada menina é responsável pelo seu caminho de crescimento e desenvolvimento juntamente com os filhos, se assim o desejar. Caso não queira é livre para se retirar, mesmo sendo menor. O acompanhamento, portanto, ocorre em todas as dimensões da pessoa humana no contexto em que se encontra inserida cada menina e menino, conforme apresentamos no esquema abaixo:

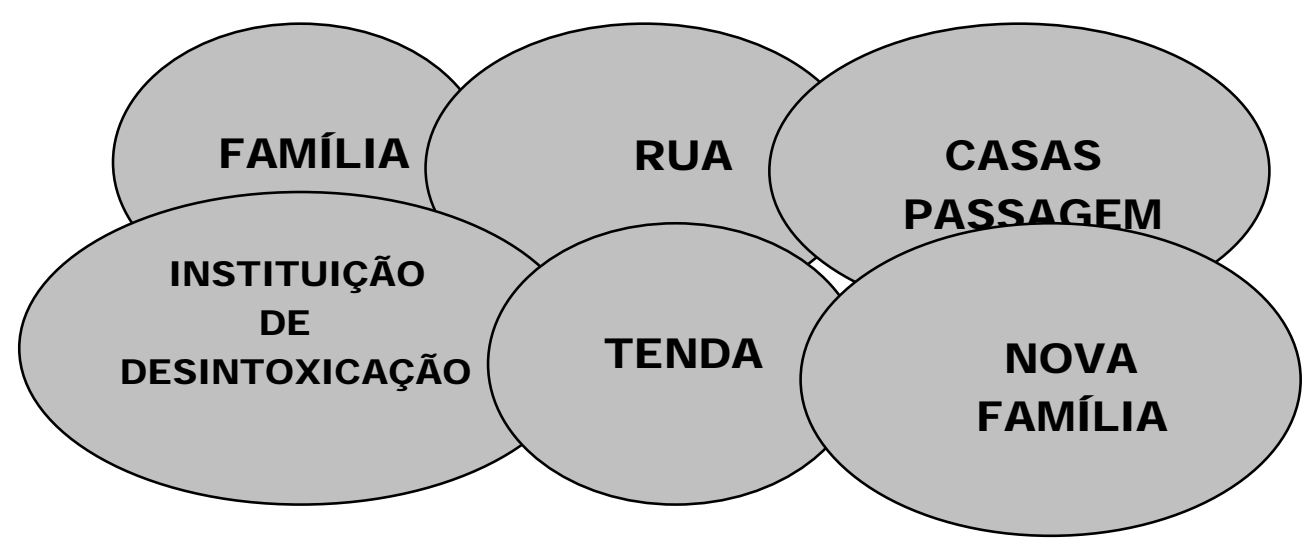

A Instituição responsável, parte do princípio de que toda pessoa é portadora dos direitos de igualdade e dignidade, como também é um ser único, individual, irrepetível, criatura racional e livre, é uma pessoa que tende à plena realização de si mesmo, numa integração harmônica de seus componentes bio-psico-social e espiritual, onde seu estatuto ontológico é caracterizado pela abertura do amor em direção ao absoluto para o qual é intrinsecamente orientado, em direção aos outros, ao mundo, à história. CRUZ (1993, p.67) considera a ação educativa como "uma arte difícil, cujo fruto é o homem, a pessoa madura, capaz de inserir-se no mundo com o conhecimento de si mesmo, dos outros, de Deus e do valor da vida. É uma pedagogia centralizada nos destinatários, sobre suas necessidades de felicidade, busca de sentido, fome de valores"

\section{Princípios pedagógicos da "Tenda"}

Antes de a menina vir morar na "Tenda" é realizado um trabalho diretamente na rua, onde através da pedagogia do encontro, somos uma presença solidária na vida destes grupos (meninos e meninas em situação de rua que, nas casa de desintoxicação, em instituições cumprindo medidas sócio-educativas, os que se encontram presos, que estão na "Tenda" e ainda as que já foram 
encaminhadas para o mundo do trabalho e casa própria).

A Instituição atua na prevenção terciária, que segundo CRUZ (1993, p.27) ela realiza um trabalho específico onde a prevenção terciária se dirige(...) à pessoas que já estruturaram um comportamento social inaceitável; mais propriamente se deveria dizer, que já experimentaram o desencaminhamento do tipo secundário, talvez já tenham interiorizado uma ou mais formas de estigmas e por isso aceitaram ou assumiram uma lenta transformação de sua personalidade, até a formação de uma identidade negativa generalizada.

Esta ação educativa encontra-se fundamentada em alguns alicerces como a relação interpessoal, o diálogo, a bondade e a firmeza, acompanhados da prudência, paciência, misericórdia e perdão.

\section{SUJEITOS DA HISTÓRIA}

Conforme descrevemos na metodologia daremos aos sujeitos entrevistados nomes fictícios da fauna e flora para preservar suas identidades. Mesmo que a opção de alguns nomes apareçam no masculino estão atribuídos aos sujeitos femininos pela relevância do seu significado.

São pessoas marcadas profundamente pelas condições desfavoráveis de vida, mas ao mesmo tempo carregam em si uma força, uma determinação e inteligência que as capacitam a superarem os desafios do vício, do vínculo com o mundo do crime e todos os tipos de atrocidades e defenderem a vida como jamais foram defendidas.

\section{Ipê Roxo}

É hoje uma jovem com vinte quatro anos de idade, sorriso aberto, acolhedor, mãe apaixonada por seus dois filhos, um de nove anos e o outro de sete. Cursa Serviço Social em uma Universidade particular através de bolsa de estudo.

\section{Ipê Branco}

Destaca-se no bairro em que mora pelo seu bom humor que contagia a todos. Gosta de esportes e entre eles jogar futebol e truco. É esbelta, possui um sorriso largo, está concluindo seu último ano do ensino médio.

\section{Azaléia do Cerrado}

Disposta, se destaca pelo cuidado para com os filhos, gosta de vê-los bem alimentados e livres para brincar. Encontra-se grávida do quinto filho, batalhadora. Está sempre de bem com a vida.

\section{Ipê Amarelo}

Reservada, tímida, protetora, e amiga, de forma especial das pessoas que como ela viveu a experiência de rua. Encontra-se grávida do quarto filho. Gosta de costurar, não abre mão dos seus filhos, uma menina de sete anos, e um menino de dois anos.

\section{Ipê Rosa}

Em muitos momentos de sua vida sente-se frágil com seu estado de saúde por possuir traços da anemia falciforme. Sua maior alegria é quando está trabalhando e tem a possibilidade de comprar as coisas para seu filho de um ano e dois meses. Por ainda ser menor (16 anos) e legalmente não Ihe ser permitido morar sozinha sem um parceiro de maior idade ou um responsável, encontra-se na Tenda aguardando a maioridade para ser encaminhada.

\section{Garça Branca}

Determinada em conquistar o que quer, lutadora e dinâmica. Cuida de seu filho de dois meses. Sente-se imensamente feliz em ter sua casa própria e ter concluído seus estudos de ensino médio. Todos a conhecem pelo seu andar ligeiro e força de vontade. Foi para a rua com 14 anos.

\section{Ipê Pardo}

Atualmente reside com sua irmã que também viveu em situação de rua, numa pequena casa deixada por sua mãe que faleceu em 2005 de cirrose alcoólica. Possui três filhos, dois meninos um de sete e o outro de um mês e uma menina de três anos.

\section{AS HISTÓRIAS DE VIDA}

As histórias de vida serão apresentadas a partir dos três núcleos temáticos, onde destacaremos algumas falas que representam as categorias.

\section{A vinda para a rua}

Identificamos através das falas que a vinda para a rua está ligada aos fatores da desestrutura familiar, violência doméstica, violência sexual, abandono familiar, influência de amigos e desafio.

" ai eu fui né me envolvendo com os meninos da rua mesmo as amizades além de ser do colégio a gente começou a se envolver com os meninos da rua".( Ipê Roxo).

"Não passava pela minha cabeça é morar na rua, morar longe da minha mãe assim não. Mais ai teve um dia que uma amiga minha falou assim, pra mim eu levei como desafio". ( Ipê Branco).

"Porque não tinha o apoio de minha mãe, morei com ela um tempo, não deu certo, porque ela era casada com outro homem, então nós dois não se dava muito bem".

"Antes de ir pra rua? Ah! Eu não dava bem com a minha família não... meu padrasto sabe? Meu padastro bebia muito, batia na minha mãe, sabe? Minha mãe grávida, e eu ficava vendo aquelas coisa e queria dar dinheiro pra abusar 
de mim, pra mim transar com ele, queria pegar no meu peito..." (Sempre- Viva).

Estas experiências negativas apresentam conseqüências na trajetória de vida destas pessoas de forma a comprometer sua auto-estima, o que requer das instituições e pessoas que atuam diretamente com estes sujeitos, competência para atuar e implementar intervenções que possibilitem a busca do autoconhecimento e enfrentamento às situações de conflito da própria vida. Dai a importância em garantia a formação contínua dos profissionais (BEZERRA, 2003) e das pessoas que estão neste processo de reconstrução da própria vida.

\section{$A$ vida na rua}

Esta categoria apresenta o cotidiano de crianças e adolescentes neste contexto, com as suas características próprias. Aqui também estão presentes as atividades lícitas e ilícitas que desenvolvem para garantir a sobrevivência; a linguagem própria;a ausência de um adulto que seja responsável pela sua educação; regras próprias de convivência e sobrevivência inerentes às pessoas que vivem nas ruas; a "liberdade" mascarada na forma de violência; uso de drogas; discriminação; ausência de "responsabilidades"; relações de poder, prostituição, gravidez e até mesmo a morte. Como exemplos deste momento da vida das nossas entrevistadas:

“... na minha cabeça tinha assim que eu fazia o que eu queria né. Eu não tinha mais pai e mãe pra manda ni mim, pra mim bater por causa de alguma coisa errada... Eu pedia, eu roubava, eu usava a droga que eu queria, eu dormia a hora que eu queria".

"Eu era a mais novinha... nove anos... Eu lembro até hoje. E foi indo, um, começou a mim ensinar a cheirar cola,... outro já foi mim ensinar outra coisa, fumar maconha, fumar cigarro, passei a beber e nisso eu já não queria mais a minha mãe, não tinha mais vontade de voltar pra minha mãe, tava gostando, nem meu avô conseguia mim tirar mais... das ruas". (Azaléia do Cerrado)

"Ai cheguei lá na rua, conheci os meninos, mim inturmei com eles, ai eu já usava, já era acostumada a usar drogas. Ai fui usando, usava, ai eu cheirava cola pra mim poder sobreviver, porque a cola corta a fome." (Ipê Rosa)

A rua muitas vezes se apresenta como único lugar de viver para quem é desprovido dos cuidados familiares e do estado, onde por sua vez inicia-se um processo de desraizamento dos vínculos familiares e em contra partida criam-se outros com os grupos que de certa forma representam neste contexto a proteção. Sendo assim, cada menina e menino deverão desenvolver habilidades específicas para criar relações interpessoais com o grupo e apreender as regras de convivência específicas destes sujeitos (NEIVA-SILVA,2003).

\section{$A$ vida além das ruas}

De um modo geral apreendemos das narrativas das histórias de vida das meninas o resultado de uma relação interpessoal entre educador e educandos que possibilitou a abertura dos sujeitos para acolherem propostas novas de vida e a saída do espaço "rua", o abandono das drogas, o processo realizado na instituição de desintoxicação, a relação educador educando, etc. Fatores estes que facilitaram no processo de resgate da rua, junto a Instituição de Desintoxicação, a "Tenda", e junto à Nova Família.

Identificamos nas falas dos sujeitos as novas perspectivas de vida frente à gravidez, ao abandono das drogas, à possibilidade de conquistar a moradia própria e de se auto sustentar juntamente com seus filhos. As atividades, portanto desenvolvidas na "Tenda" como casa lar, aparecem como potencializadoras destas conquistas. Conforme apresentamos nas narrativas abaixo.

“... Eu já tinha passado por vários abrigos, mas só que ai parece que um deles mexeu comigo... eu fiquei lá seis meses e fui pra rua de novo por causa de droga, eu queria usar droga. Ai quando eu voltei, eu fui pra uma fazenda de recuperação (desintoxicação) e não queria mais droga na minha vida. E queria lutar pra ficar com os meus filhos... agente tem uma convivência lá de família... Tenda é tudo é a casa da minha mãe, é meu lar"(Ipê Roxo)

"Medo. A solidão é a dificuldade maior... Medo de encarar a realidade, medo da vida. Medo dos problemas. A solidão de enfim, ficar sozinha, não ter alguém para conversar"(Ipê pardo)

"... aprendi a viver sem as drogas, nessa $2^{a}$ vez que eu fui pra Tenda e fiquei os sete meses, eu já não sentia mais falta é tinha as amigas minhas lá também a gente conversava muito e esqueci das drogas. Assim meus vícios foram outros... subir na vida, melhorar de vida... Ah minha recuperação eu atribuo logicamente a Tenda de coração....." (Ipê Branco)

"eu vejo lá como minha casa, até hoje né. Como a minha casa que eu posso chegar e né, chegar e entrar assim, como minha casa mesmo. Né lá, tá certo, lá tem normas, que deve ser cumprida, mas fora isso, e é o que ajuda lá é isso né, são as normas". (Ipê Rosa)

Identificamos um consenso nas narrativas ao afirmar que o acompanhamento realizado pela equipe 
no espaço da rua e fora dela proporcionou um forte vínculo com os sujeitos e a partir deste, juntamente com o momento epifanico que foi desencadeado em cada história e que aparece na vida de seis meninas, a gravidez, fez emergir o desejo de sair da rua e assumir outra proposta de vida.

Ao que se refere à "Tenda" e a pedagogia aplicada identificamos a contribuição no processo de recuperação do grupo preenchendo em muitos momentos da história de vida destas pessoas lacunas que se encontravam rompidas ou fragmentadas pelas experiências anteriores. Foram capazes de redimensionar o valor de ser mãe, de construir uma família e ao mesmo tempo resgatar algumas relações humanas com seus genitores.

Ocorre portando um resgate da auto estima, expresso no desejo de cuidar de si e do outro, promove o auto -sustento, a volta à escola, a inserção no mundo do trabalho, como também a conquista de valores e bens materiais a partir dos esforços e potencialidades que foram sendo resgatadas $e$ fortalecidas. Notamos em todas as falas a presença forte da exclusão social e a descrença das pessoas ao que se refere à recuperação destes sujeitos que são vistos com desconfiança e com incapacidade para dar rumos diferentes à própria vida.

Neste sentido sentimos a necessidade de resgatarmos também alguns valores sociais que foram assumidos pela nossa Constituição conforme nos fala SHIRATORI et al (2003, p215), que "a dignidade da pessoa humana apresenta-se contemplada na Constituição federal como um direito individual de proteção e em relação ao tratamento igualitário que devem receber todas as pessoas. Como dever configura-se na exigência do indivíduo respeitar a dignidade de seu semelhante tal qual a constituição Federal exige que the respeitem a própria".

Identificamos neste núcleo temático o processo de recuperação; a "Tenda"; Resgate da auto-estima; e a inclusão social. Todas estas etapas se apresentaram em um contexto interligado, e o que desencadeou esta mudança foi o confronto com a própria realidade a partir de uma relação inter pessoal entre educador e educando, sonhos, acontecimentos pessoais como a gravidez, e o desejo em mudar de vida. Cada situação fez emergir um comportamento diferente daquele ocorrido em sua saída de casa para a rua, mas todos marcados por uma grande mudança nos rumos de suas vidas.

Ao analisarmos o caminho percorrido pelos sujeitos na perspectiva da inclusão social sentimo-nos no dever de considerar os esforços exigidos a nível pessoal e institucionais para que estes sujeitos cheguem ao apoderamento de algumas habilidades para trabalharem transtornos como a "síndrome da dependência e abstinência" (KAY et al, 2002, p.188) que acompanham suas vidas como usuário de substâncias, uma vez que segundo as narrativas, foram vários os tipos de drogas que utilizaram, e isso requer dos sujeitos determinação e coragem.

\section{CONCLUSÃO}

De acordo com as narrativas dos sujeitos o processo de recuperação e re-inserção social, podemos perceber a importância da gravidez nesse processo. Talvez seja esse um momento de reflexão na vida da menina, repentinamente se vê ante a necessidade de assumir uma postura diferente diante à própria vida, com responsabilidade e possibilidade de oferecer um novo futuro à propria vida e à do filho. No entanto, nesse processo de despertar para novas perspectivas de vida as ações pedagógicas desenvolvidas na Instituição, assim como a convivência com os educadores cumprem um papel significativamente importante na medida que se propõe enquanto um espaço integrador, articulador, de suporte e,em especial de ajuda à menina a descobrir sobre sua própria vida.

Esse aspecto corrobora o que MEDEIROS (1999) aponta, que o abrigo para crianças e adolescentes com experiência de vida nas ruas deve oferecer muito além do que um espaço físico para abrigá-los, tornando-se mais atrativo do que a rua. Este mesmo aspecto RIZZINI et al (2005) também abordam ao apontar que as instituições devem assumir a defesa da vida, de forma a contribuir e encorajar as crianças e adolescentes que vivem nesses locais, proporcionando condições para enfrentem os seus próprios conflitos sejam de natureza interna (psicológicos) ou externa (fatores econômicos e sociais). Portanto, nesse processo de reintegração, o papel do educador merece destaque à medida que transmitem segurança, confiança e coragem para que enfrentem as adversidades da vida.

Dessa maneira, por meio das histórias orais de vida, foi possível identificarmos a trajetória dos sujeitos, a inclusão social no processo de recuperação, assim como a importância de um trabalho sistematizado, contínuo de respeito ao outro, por meio de um trabalho institucionalizado que, no caso desse estudo denominamos "Tenda" que tem como significado ser um espaço de acolhida, suporte e potencialização de valores e resgate na reestruturação de vida das adolescentes e, porque não dizer, de seus filhos.

\section{REFERÊNCIAS BIBLIOGRAFICAS}

BARDIN, L. Análise de conteúdos. Lisboa: Edições 70, 1977.

BEZERRA,A.L.Q. O contexto da Educação continuada em enfermagem. São Paulo:Lemar e Martinari, 2003.

CÂMARA, M. F. B.Aparato de apoio social à juventude: reflexões acerca do discurso intersetorial. 2003. 164p. Dissertação (Mestrado em Saúde 
Pública) - Escola de Enfermagem de Ribeirão Preto, Universidade de São Paulo, Ribeirão Preto (SP).

CRUZ, I. P. S. P. Tradução Ir. Mirtes Cherobim. A caminho de um projeto educativo passionista: marco referencial. São Paulo: Ed. Loyola, 1993.

FERREIRA, A. B. H. Novo Dicionário da língua portuguesa. $2^{\mathrm{a}}$ ed. Rio de Janeiro: Nova Fornteira, 1989.

HIRATA, M. C. Crescer na adversidade - um toque na auto-estima dos adolescentes: a poética das flores. Salvador: Ultragraph, 1999.

KAY, J.; TASMAN, A.; LIEBERMAN, J. A. Trad. Eliseanne Noppa. Psiquiatria: Ciência comportamental e fundamentos clínicos. São Paulo: Manole, 2002.

LUSK, M. W. Street children programs in Latin America. Journal of sociology and Social Welfare, v. 16, n. 1, p. 55-77, 1989.

MEDEIROS, M. Olhando a lua pelo mundo da rua: epresentações sociais da experiência de vida de meninos em situação de rua. 1999, 170p. Tese (Doutorado) Escola de Enfermagem de Ribeirão Preto da Universidade de São Paulo. Ribeirão Preto.

MEIHY, J. C. S. B. Manual de História Oral. 4a ed. São Paulo: Loyola, 2002.)

MINAYO, M. C. S. O Desafio do conhecimento:

Pesquisa qualitativa em Saúde. São Paulo/ Rio de

Janeiro: Hucitec - Abrasco, 1992.

MIRANDA, C. F.; MIRANDA, M. L Construindo a

relação de ajuda. $9^{a}$ ed. Belo Horizonte: Crescer,

1995.

NEIVA-SILVA, L. Expectativas futuras de adolescentes em situação de rua: Um estudo autofotográfico. 2003. 176p. Dissertação (Mestrado). Instituto de Psicologia da Universidade Federal do Rio Grande do Sul. Porto Alegre, RS.

OLIVEIRA, N. S.; MEDEIROS, M.; MUNARI, D. B. Aspectos da auto-estima de crianças e adolescentes em situação de rua: reflexões para o cuidado em Enfermagem. Revista Ciência, Cuidado e Saúde, v. 3 n. 3, p. 233-242, 2004.

OLIVEIRA,N.S. Interação da equipe de saúde com meninos e meninas em situação de rua: aspectos preliminares. In: CONGRESSO BRASILEIRO DE ENFERMAGEM, 53, Curitiba, 2001. Anais. Curitiba, 2001.

A coragem de ser e fazer enfermagem na perspectiva da pedagogia social de rua. In: CONGRESSO BRASILEIRO DE ENFERMAGEM, 56, Gramado (RS), 2004. Anais. Gramado, 2004a.

Os profissionais de Enfermagem e a violência doméstica. In: CONGRESSO BRASILEIRO DE ENFERMAGEM, 56, Gramado (RS), 2004. Anais. Gramado, 2004b.

Ser e fazer enfermagem no cotidiano de crianças e adolescentes em situação de rua, vítimas de violência. In: CONGRESSO BRASILEIRO DE ENFERMAGEM, 56, Gramado (RS), 2004. Anais. Gramado, 2004c.
OLIVEIRA,N.S. Histórias de vida de meninas com experiência pregressa nas ruas: Perspectivas do processo de inclusão social. 2006.189p. Dissertação (Mestrado). Faculdade de Enfermagem da Universidade Federal de Goiás. Goiânia (GO).

REINALDO, A. M. S. Conhecendo o intinerário terapêutico em saúde mental pela história oral de vida do paciente psiquiátrico. 2003. 113p. Dissertação (Mestrado). Escola de Enfermagem de Ribeirão Preto, Universidade de São Paulo. Ribeirão Preto, SP.

REMEN, R. N. O paciente como ser humano. $2^{\mathrm{a}} \mathrm{ed}$. São Paulo: Summus, 1993.

RIZZINI, I.; BARKER, G.; CASSANINGA, N. Políticas sociais em transformação: crianças e adolescentes na era dos direitos. Educar em revista, n. 15, 1999. Disponível em http:// www.educaremrevista.ufpr.br [Acesso em: 11 ago.2005.]

SHIATORI, K.; FIGUEIREDO, N, M. A.; PORTO, F.; SILVA, C. S. I.; TEIXEIRA, M. S. O sentido de ser Humano: uma base reflexiva. Revista de Enfermagem da UERJ. V. 11; n, 2, p. 212-216, 2003.

WALDOW, V. R Cuidado humano: O resgate necessário. 3a ed. Porto Alegre: Sagra - Luzzato, 2001.

Texto recebido em 30/03/2006

Publicação aprovada em 30/04/2006 